Document downloaded from:

http://hdl.handle.net/10251/100591

This paper must be cited as:

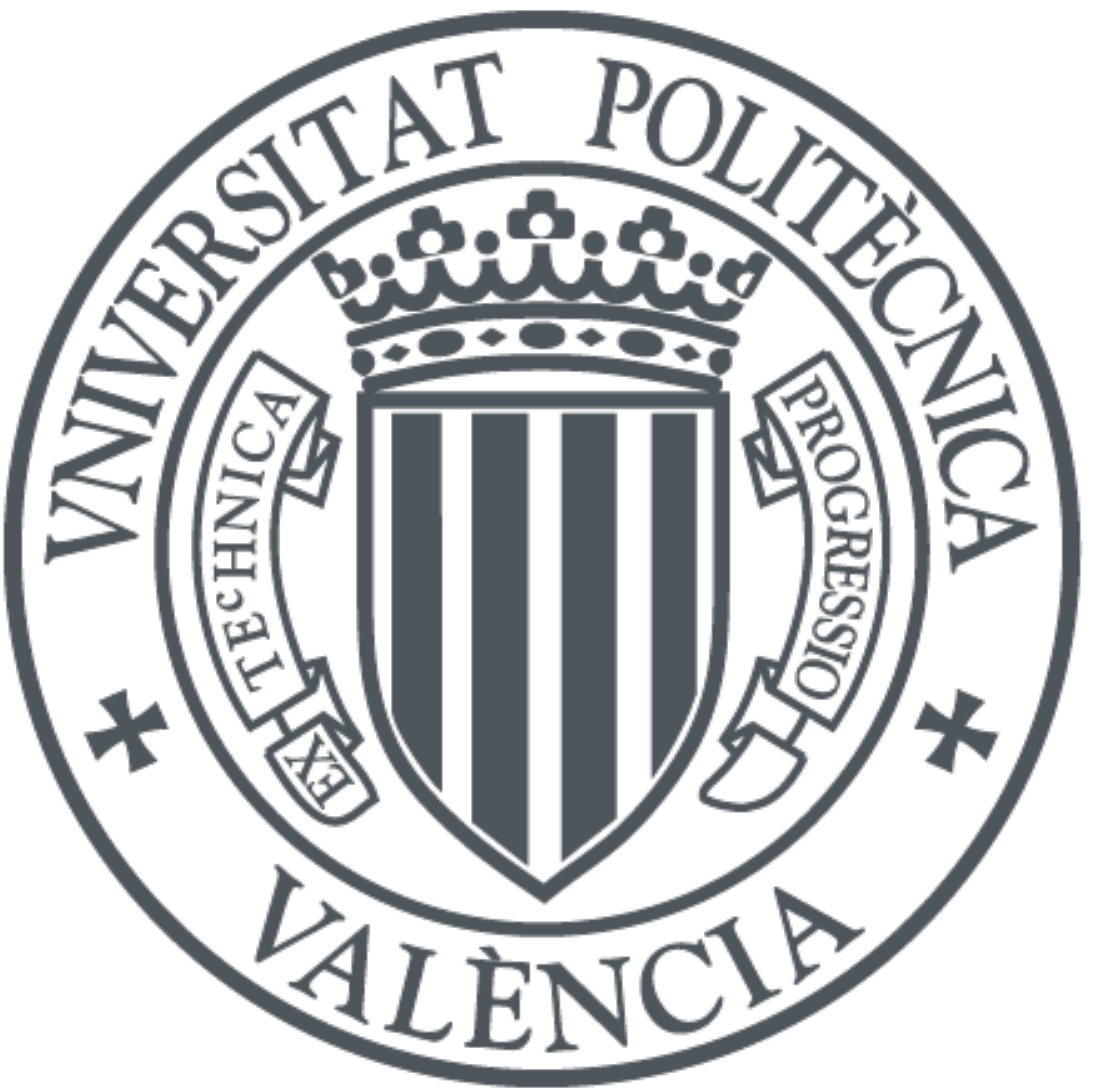

The final publication is available at

https://doi.org/10.1179/174329009X449323

Copyright MANEY PUBLISHING

Additional Information 


\title{
Fabrication of ultrafine and nanocrystalline WC-Co mixtures by planetary milling and subsequent consolidations
}

\author{
V. Bonache*, M. D. Salvador, D. Busquets and E. F. Segovia
}

In this work ultrafine and nanocrystalline WC-Co mixtures were obtained by low energy milling in planetary ball mill. The effect of the processing conditions on the reduction and distribution of the grain sizes and the internal strains level were studied. The characterisation of the powder mixtures was performed by means of scanning and transmission electron microscopy and X-ray diffraction analysis. Observations through SEM and TEM images showed a particle size below $100 \mathrm{~nm}$, after milling. The X-ray diffraction profile analysis revealed a WC phase refined to a crystallite size of $19 \mathrm{~nm}$.

The mixtures obtained have been consolidated and mechanical and microstructurally characterised. The results show improvements in resistant behaviour of the material consolidated from nanocrystalline powders, in spite of the grain growth experienced during the sintering. The best results were found for the material obtained by wet milling during $100 \mathrm{~h}$, which presents values of hardness higher than $1800 \mathrm{HV}$.

Keywords: WC-Co, Planetary ball mill, Nanocrystalline powders, Microstrain, Mechanical properties

\section{Introduction}

Cemented carbides are being used in cutting tools due to their high hardness, mechanical strength, good high temperature behaviour and superior wear resistance. ${ }^{1}$ In these cases, the system $\mathrm{WC}-\mathrm{Co}$ is the most utilised in the industry. The properties of $\mathrm{WC}-\mathrm{Co}$ cermets mainly depend on composition, microstructure and carbide purity. ${ }^{2,3}$ In general, reducing WC grain size improves mechanical properties, increasing hardness, wear behaviour and transverse rupture strength without compromising toughness. ${ }^{4,5}$

Traditionally $\mathrm{WC}-\mathrm{Co}$ cermets have been produced by sintering of micrometric powders $(1-4 \mu \mathrm{m})$. Looking for higher mechanical properties and the needed of smaller and higher precision tooling has led to the use of finer powders, being classified as submicrometric $(<0 \cdot 6 \mu \mathrm{m})$ and ultrafine $(<0.3 \mu \mathrm{m})$ which have showed their excellent potential of improvement. ${ }^{6-8}$ In this way, after being used for specific tooling in the wood and electronic industry the uses have extended to cutting tools for other materials (ferrous, non-ferrous, plastics) and industries (general machining, mining, casting, etc). ${ }^{9,10}$

Powder size reduction to nanometric scale and development of nanostructured coatings and bulk materials are nowadays an important subject of research and have emerged as very promising materials. ${ }^{10,11}$ In

Instituto de Tecnología de Materiales, Universidad Politécnica de Valencia, Camino de Vera, S/N, Valencia 46022, Spain

*Corresponding author, email vicbobe@ doctor.upv.es the case of cermets, nanostructured materials are considered those with a grain size smaller than $100 \mathrm{~nm}$ in which the high grain boundary to volume ratio enlarge the margin of improvement in their properties. ${ }^{12}$ This fact has led to an important increase in demand on nanocrystalline WC powders and $\mathrm{WC}-\mathrm{Co}$ mixtures and therefore the means of producing them. Among others, rapid carburisation, ${ }^{13}$ spraying conversion, ${ }^{14-16}$ thermochemical precursor reduction, ${ }^{17}$ hydrogen plasma reduction, ${ }^{16,18}$ integrated mechanical and thermal processing ${ }^{19}$ and high energy milling ${ }^{1,12,20-24}$ are the most used.

High energy milling is the most versatile technique for the production of nanostructured materials, because it is relatively straightforward and requires low investments. $1,11,24$

However, the milling process lacks of efficiency due to the high energy consumption, the long processing times and the incorporation of some degree of impurities. , 19,20 $^{2}$

Recent developments in high energy milling have enabled the production of nanometric WC-Co mixtures with relatively short processing time and low contamination when inert atmospheres or wet conditions are achieved. ${ }^{1,23-25}$ On the other hand, although cryogenic high energy milling has been recently under study by some researchers, there has not been a significant improvement in the quality of the powders. ${ }^{25}$

Therefore, the aim of this work is to optimise the milling conditions in planetary ball milling to obtain nanocrystalline $\mathrm{WC}-\mathrm{Co}$ mixtures from commercial micrometric WC and Co powders. For this purpose, the influence of milling times and medium are correlated 
to the crystallite size reduction and particle size distribution, contamination and the presence of internal microstrains. In order to evaluate the effect of the milling parameters, in the densification, microstructural development and mechanical properties of the final product, the sintering behaviour of $\mathrm{WC}-12 \mathrm{Co}$ mixtures obtained has been studied.

\section{Experimental}

Commercial micrometric powders from $\mathrm{WC}$ and Co were purchased from Sigma Aldrich with a mean particle size of 10 and $2.5 \mu \mathrm{m}$ respectively. In all cases the ratio of WC-Co mixtures was fixed to be $12 \mathrm{wt}-\% \mathrm{Co}$ as the influence of $\mathrm{Co}$ in the reduction of $\mathrm{WC}$ grain size is negligible and on the contrary a higher amount will minimise the impacts during milling. ${ }^{25}$ The reason for milling the powder mixture instead of the elements separately is two-fold: a reduction in the Co crystallite size is promoted in a first instance and second there is a homogeneous distribution of the cobalt around the particles in such a way that sintering behaviour is improved. $^{26}$

Milling have been carried out in a planetary ball mill from Retsch, using a WC container $500 \mathrm{~cm}^{3}$ in volume with $10 \mathrm{~mm}$ in diameter WC balls. The ball powder ratio was $10: 1$ in any case. Milling speed has been chosen in agreement with the optimum operation values of $65-$ $85 \%$ of the critical speed and set to $250 \mathrm{rev} \mathrm{min}^{-1}$. rotating direction was alternated each $10 \mathrm{~min}^{24}$ Processing has been carried out under dry and wet conditions. In the former, a stearate based lubricant ( $1 \mathrm{wt}-\%)$ has been added and protective atmosphere (argon) has been used while milling. In the latter, processing took place with the addition of isopropyl alcohol ( $70 \mathrm{wt}-\%$ of the mass of powders). After wet milling, powder mixes have been dried in the same container at $110^{\circ} \mathrm{C}$ during $2 \mathrm{~h}$. Once dried, the powders have been mixed in a final milling stage under argon atmosphere during $2 \mathrm{~min}$ at $250 \mathrm{rev} \mathrm{min}^{-1}$.

Characterisation of powder morphology and size have been carried out for all the mixtures by means of a JEOL JSM 6300 scanning electron microscope (SEM) and a 100 kV Philips CM10 transmission electron microscope (TEM). Powder dispersions for TEM observation were prepared by included ultrasonic mixing in ethanol. Semiquantitative energy dispersive $\mathrm{X}$-ray analysis (EDX) fitted in the SEM has been used for a first approach to the analysis of powder contamination.

For the study of the evolution of crystalline phases Xray diffraction (XRD) technique has been used, by means of a Bruker Theta model D8 advance apparatus,

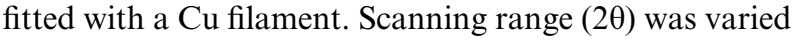
from 20 to $90^{\circ}$ and ICDD PDF-2 (2004) database was used for phase identification.

Crystallite size and internal stress have been determined by XRD profile analysis. ${ }^{9,20,21,23,24}$ For the first purpose, the Scherrer equation has been used, in which the broadening of the peaks is attributed to the reduction in crystallite size by equation (1)

$$
D_{\mathrm{hkl}}=\frac{0 \cdot 89 \lambda}{\beta(2 \theta) \cos (\theta)}
$$

where $\beta(2 \theta)$ is the full width at half maximum (FWHM), $\lambda$ is the $\mathrm{X}$-ray wavelength (in this case $\mathrm{Cu} K_{\alpha}$ radiation have been used, $\lambda=0 \cdot 15406 \mathrm{~nm}$ ), and $D_{\mathrm{hkl}}$ is the crystallite mean size.

In order to estimate the contribution of both factors, i.e. crystallite size and internal stress, the Stokes-Wilson approach, has been followed

$$
\beta=\beta_{\mathrm{d}}+\beta_{\varepsilon}=\frac{0 \cdot 89 \lambda}{d \cos (\beta)}+4 \varepsilon \tan g(\theta)
$$

where $\beta$ is the FWHM of diffraction peak after instrumental correction, $\beta_{\mathrm{d}}$ and $\beta_{\varepsilon}$ are the peak broadening associated with size reduction and internal stresses respectively, $d$ and $\varepsilon$ are the respective values of crystallite size and internal stress level.

The broadening instrumental have been corrected in every case using a standard sample, consisting of stress relieved WC powder with $1 \mu \mathrm{m}$ mean grain size. This correction assumes that the profile is a Gaussian and the real width could be estimated by equation $(3)^{27}$

$$
c=\left(b^{2}-a^{2}\right)^{1 / 2}
$$

where $c$ is the true peak broadening, $b$ is the FWHM of the experimental profile and $a$ is the FWHM of the standard profile. Peaks analysed in any case have been those corresponding to (0001) (10 $\overline{1} 0)$ and (10 $\overline{1} 1)$ planes.

Powder size has been measured by means of Brunauer-Emmelt-Teller surface area (BET) technique using an ASAP 2010 apparatus from Micromeritic.

Green compacts have been produced by uniaxial pressing at $250 \mathrm{MPa}$. Sintering has been carried out by two different routes: vacuum sintering at $1400^{\circ} \mathrm{C}$ for $45 \mathrm{~min}$ and glass encapsulated hot isostatic pressing (HIP) at $1250^{\circ} \mathrm{C}, 150 \mathrm{MPa}$ for $30 \mathrm{~min}$. The microstructures of the sintered materials have been characterised by SEM and energy dispersion spectroscopy. The mean WC grain size has been measured using mean lineal intercept method. The density has been determined by Archimedes' principle, using water immersion. The porosity has been obtained using quantitative metallography of polished surfaces. Vickers hardness measurements have been carried out applying a load of $30 \mathrm{~kg}$ and indentation fracture toughness $K_{\mathrm{IC}}$ has been estimated by applying the Palmqvist model to cracks generated by indentation. ${ }^{28}$

\section{Results and discussion}

During the process of milling different metallurgical mechanism can take place, depending on the nature of powders: cold deformation and cold welding in ductile phases and fracture in fragile phases. In the case of WCCo mixtures, there is a reduction in size of the carbides by continuous breakage of the particles, whereas cobalt withstands cold deformation and welding, promoting powder agglomeration.

Figure 1 shows the general appearance of powders after milling 25 and $100 \mathrm{~h}$ under both dry and wet conditions. Evolution of grain size reduction was similar to that found by other authors using high energy milling in an attritor. However, in the present work, due to the lower energy involved with the use of planetary ball milling, longer processing times were needed for reaching nanometric scale sizes. ${ }^{1}$

In the milling process, two different stages were distinguished. During the first one, up to $25 \mathrm{~h}$ of processing, a strong carbides size reduction was 

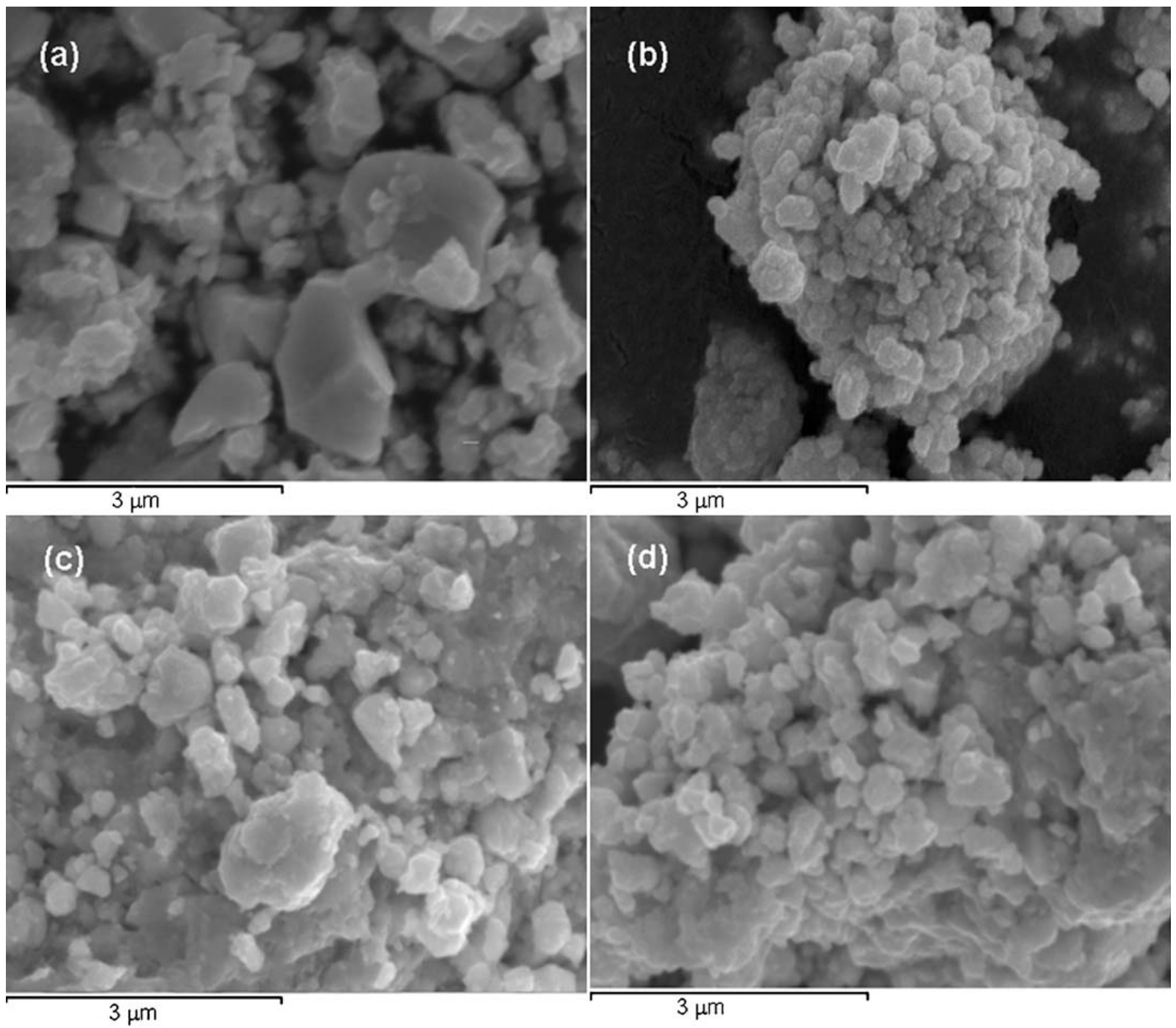

a $25 \mathrm{~h}$, wet milling; $b 100 \mathrm{~h}$, wet milling; $c 25 \mathrm{~h}$, dry milling; $d 100 \mathrm{~h}$, dry milling

1 Images (SEM) of WC-12Co powders after milling

observed. Greater size together with the cold deformation of cobalt phase also occurred. After this period, mean particle size has been reduced to $0 \cdot 8-1 \cdot 2 \mu$ m under both wet and dry media. Although there has been an important reduction in carbide size compared to the departing powders, nanometre range has not yet been attained as in other works in which higher energy processing methods have been used. ${ }^{11,24}$

During the successive time of processing, carbide size was further reduced but agglomerates started to form. The size of agglomerates increased with time, as cold welding began to become more important. This phenomenon was more accused in the case of dry milling in contrast to wet milling, as shown by the higher size of agglomerates found in the corresponding SEM images of Fig. 1.

Figures 2 and 3 show SEM and TEM images respectively of $\mathrm{WC}-\mathrm{Co}$ powders after $100 \mathrm{~h}$ milling time, in wet and dry media.

Important differences have been found when compared both processing routs. In fact, by means of wet milling nanometric carbide size has been attained, with a size mainly ranging from 20 to $60 \mathrm{~nm}$, with a minimum carbide particle size of $\sim 10 \mathrm{~nm}$. On the other hand, after $100 \mathrm{~h}$ dry milling only ultrafine powders are obtained, with carbide sizes ranging from 100 to
$250 \mathrm{~nm}$. These sizes were equivalent to $75 \mathrm{~h}$ milling time in the case of wet milling. In the latter case, TEM observation revealed the presence of carbides below $100 \mathrm{~nm}$ in size, but the number of particles of higher size was more significant (Fig. $3 b$ ).

Figure 4 shows the correlation of carbide particle size versus milling time. The size particle was determined by image analysis with specific computer software from both SEM and TEM images. At least 50 measures for each milling condition were carried out.

Figure 5 represents the reduction in carbide particle size as a function of milling time, for both processing routs, where the higher efficiency of wet processing was evident, with improvements up to $1.5 \%$ regarding the dry processing.

Energy dispersive X-ray analysis of powders after milling confirmed the no existence of impurities other than oxygen, as shown in Fig. 6. This was mainly due to the use of both jar and balls made of WC, thus minimising the incorporation of strange elements. However, in spite of the fact of using protective atmospheres in every case, the formation of higher quantity and more reactive surface area associated with the particle size reduction during milling leads to the adsorption of some oxygen. ${ }^{1}$ 


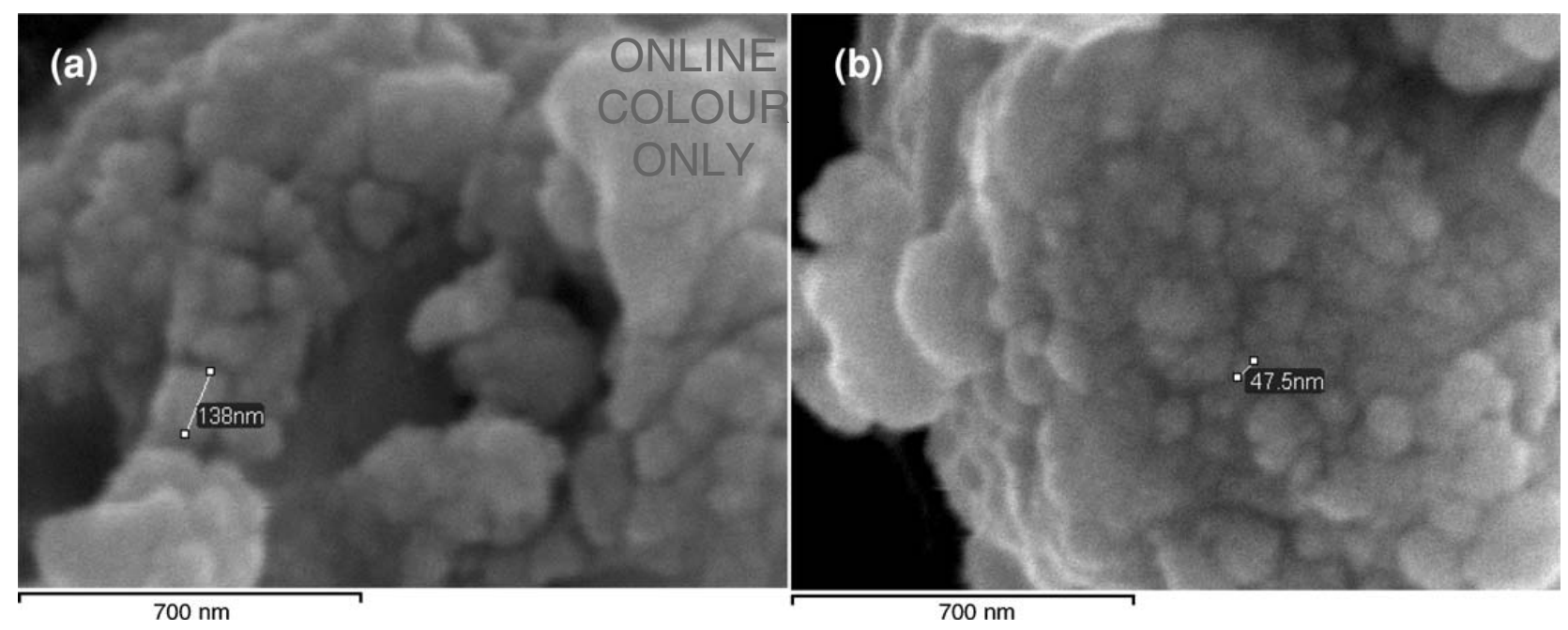

$a$ wet $(20-60 \mathrm{~nm}) ; b$ dry $(100-250 \mathrm{~nm})$

2 Images (SEM) of WC-12Co composite powders after $100 \mathrm{~h}$ milling
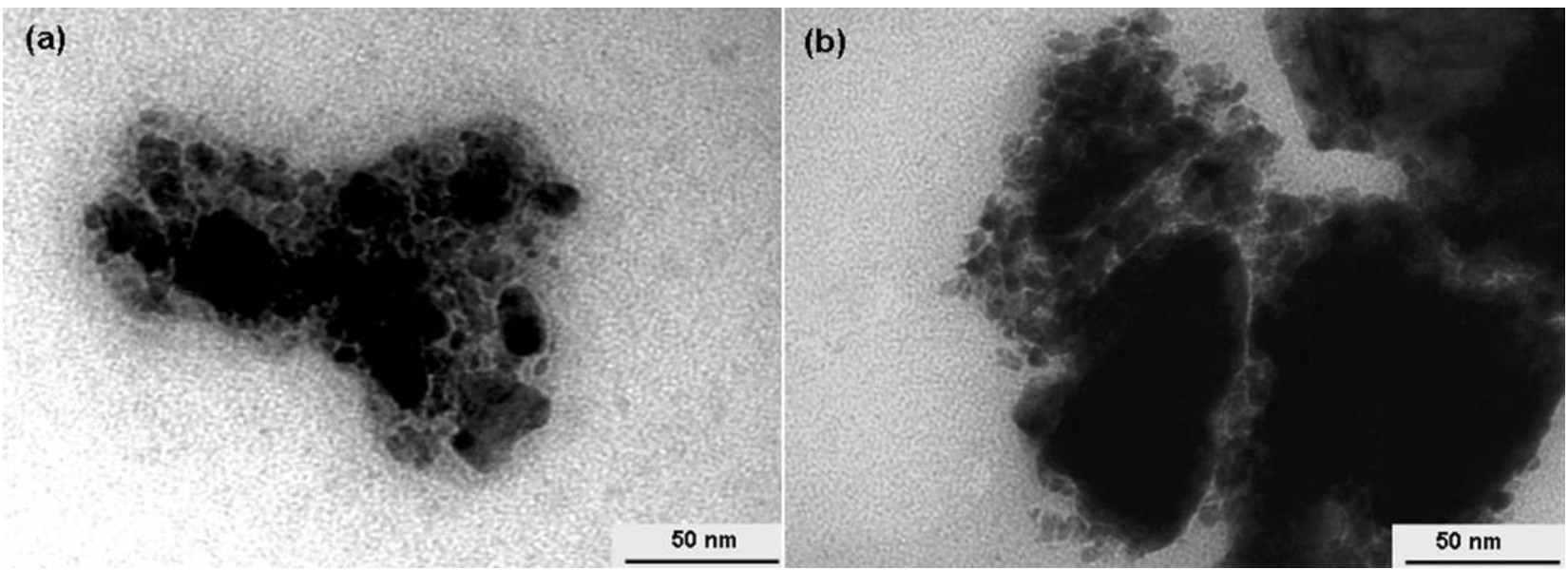

$a$ wet; $b$ dry

3 Images (TEM) of WC-12Co composite powder after $100 \mathrm{~h}$ milling

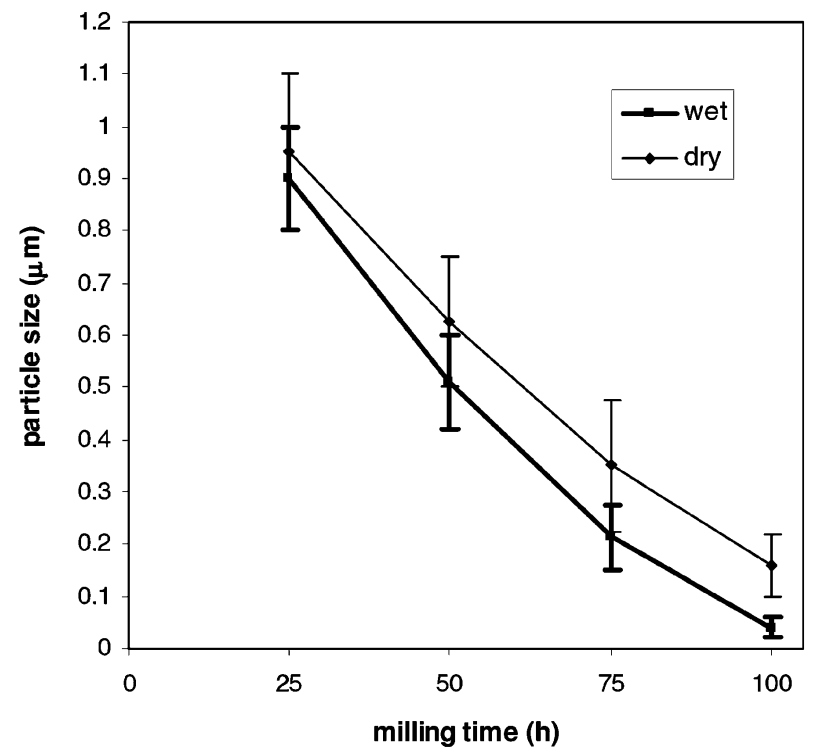

4 Evolution of WC particle size with milling time, obtained by SEM and TEM images
Table 1 presents the EDX analysis results for different time periods, in which the increase in oxygen with milling time became apparent. However, contamination was lower for those powders processed by wet milling, with a maximum of $1.26 \mathrm{wt}-\%$, value below that is

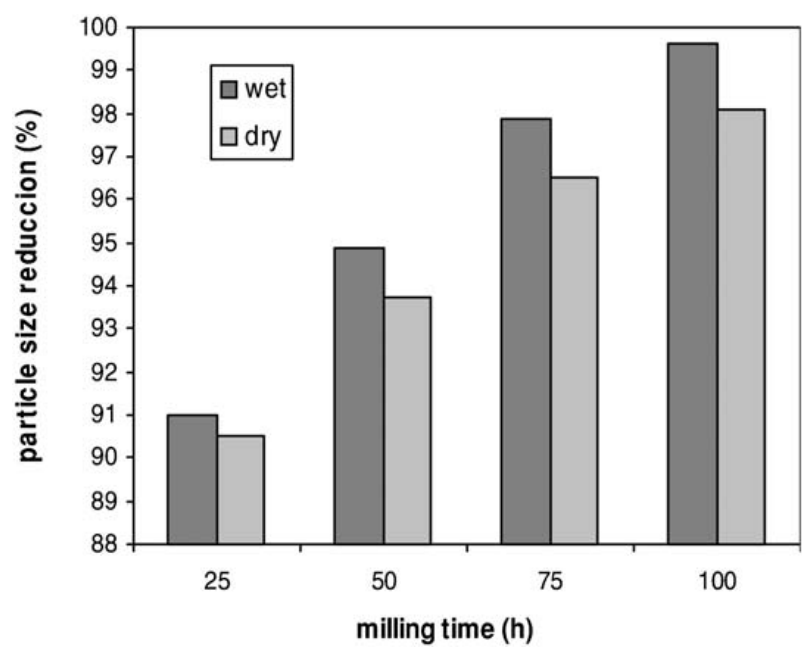

5 WC particle size reduction as function of milling time

Powder Metallurgy 2009 VOL 000 NO 000

Powder Metallurgy pom1545.3d 15/5/09 18:11:35 


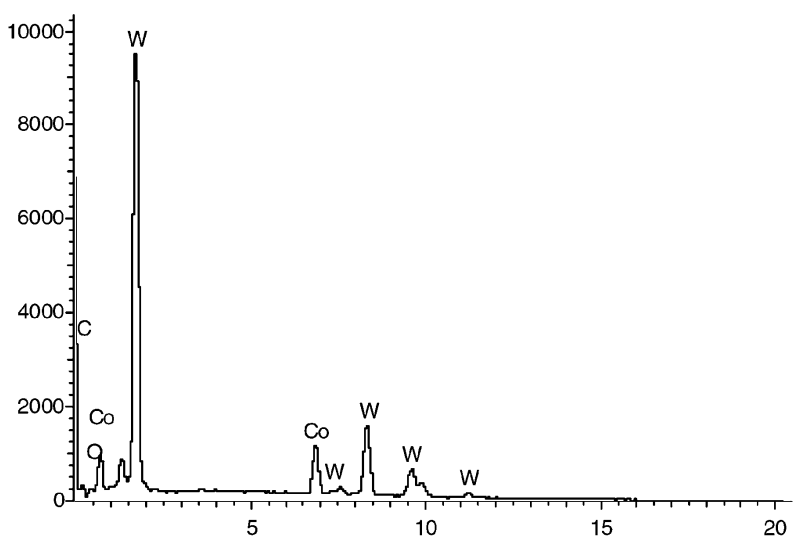

6 Energy dispersive X-ray analysis of WC-12Co powder after $100 \mathrm{~h}$ wet milling

obtained by $\mathrm{He}$ et al. using other protective media. ${ }^{29}$ Mechanisms though to be involved in these results were two: first, the better control of process temperature and second the protection of particles by a layer of liquid media, preventing the reaction of these with the remaining oxygen traces. However, when dry milling was performed, in spite of the higher oxygen levels, there was not a significant carbon loss, indicating that even in this case temperature reached was not high enough to decarburisation produced. This was a critical factor of the process as any decarburisation would be detrimental to the quality of the material. ${ }^{26}$

Apart from oxygen content, there were no other significant compositional differences. There was only a slight loss of cobalt in the case of dry milling, probably due to the higher occurrence of welding to the milling parts.

Observations through SEM and TEM were corroborated by BET technique, as a surface area of $2 \cdot 315 \pm 0 \cdot 377 \mathrm{~m}^{2} \mathrm{~g}^{-1}$ corresponding to a mean size of $173 \mathrm{~nm}$ have been obtained for $100 \mathrm{~h}$ dry milling, whereas after $100 \mathrm{~h}$ of wet milling the value obtained have been $8.478 \pm 0.434 \mathrm{~m}^{2} \mathrm{~g}^{-1}$ corresponding to a mean size of $47 \mathrm{~nm}$.

Figure 7 shows the evolution of XRD diffraction patterns of powders after processing during different times for both dry and wet milling. The first important aspect to point was the disappearance of the cobalt peak after $25 \mathrm{~h}$ milling time for both processing conditions. This effect could be attributed to the solid solution of Co in WC. However, solubility of cobalt in WC is negligible in agreement with the corresponding phase diagram. In this case, the drastic increase in surface free energy associated with the particle size reduction, together with other factors as the presence of high quantity of crystalline defects associated with the high energy

Table 1 Chemical composition by EDX of WC-12Co powders as function of milling time and rout

Milling condition

Elements, wt-\% $25 \mathrm{~h}$ wet $100 \mathrm{~h}$ wet $25 \mathrm{~h}$ dry $100 \mathrm{~h}$ dry

\begin{tabular}{lrrrr}
\hline C & 5.18 & 5.07 & 5.08 & 5.06 \\
$\mathrm{O}$ & 0.72 & 1.26 & 1.57 & 2.36 \\
Co & 12.14 & 11.75 & 11.51 & 11.23 \\
W & 81.96 & 81.92 & 81.84 & 81.35 \\
\hline
\end{tabular}
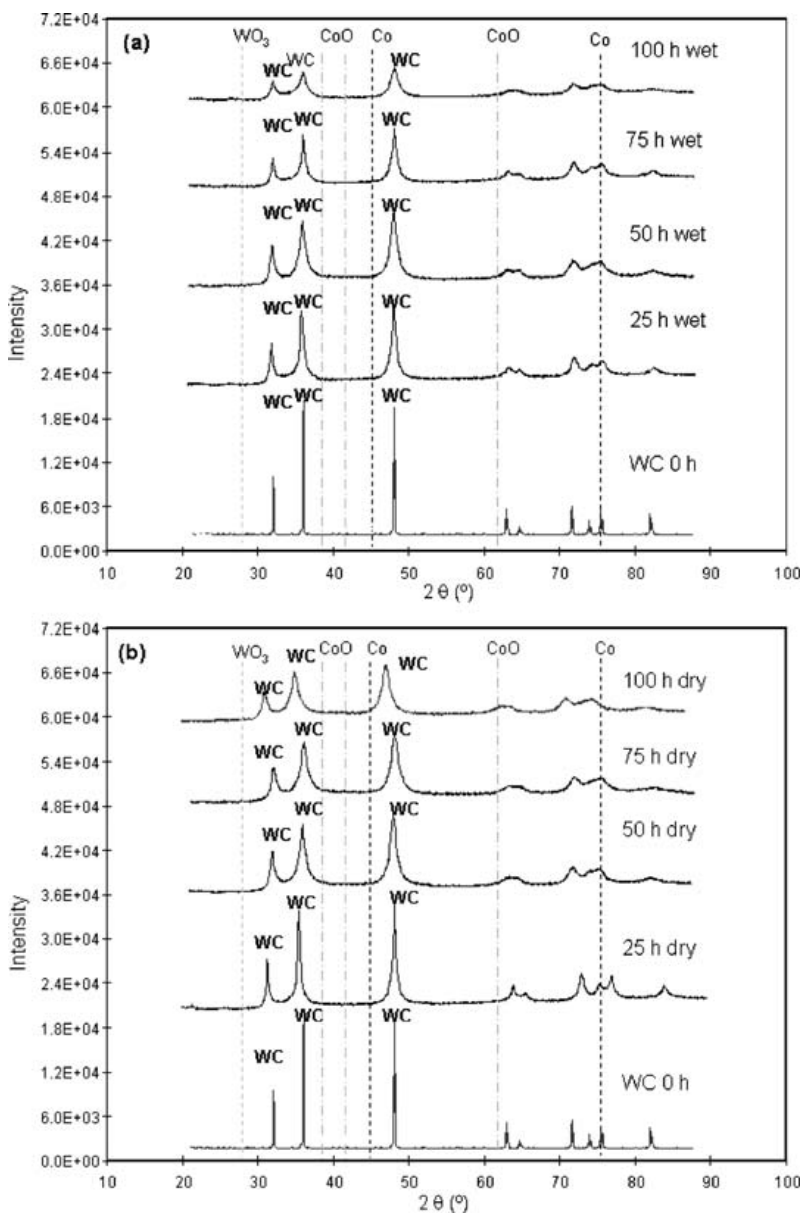

$a$ wet; $b$ dry

7 X-ray diffraction of WC-12Co powders mixture as function of milling time and processing

milling processes could justify this observed increment in solubility. ${ }^{11,23}$ This non-observation of the cobalt peak could also be attributed to its broadening associated with crystallite size reduction and internal stresses, in agreement with Back et al., who measured cobalt crystallite sizes in the range of $5-10 \mathrm{~nm} .^{25}$

On the other hand, under neither of the conditions analysed there were peaks associated with oxides, either from $\mathrm{Co}$ or $\mathrm{W}$. Therefore, it is concluded that the oxygen levels detected by EDX analysis corresponded to humidity absorption and molecular oxygen adsorption phenomena. In addition, neither $\mathrm{W}_{2} \mathrm{C}$ nor orthorhombic WC peaks are present. ${ }^{1}$

There was a peak broadening related to milling time, indicating of either a reduction of carbide size, the development of internal stresses as a result of the milling or both. ${ }^{1,11,23,25}$ This broadening effect was more important in the case of wet milling, in which the fracture of the fragile phase phenomena was prevalent over the deformation and welding of ductile phase, in agreement with SEM observations. Thus, for wet milling there is a certain degree of amorphisation in the material.

However, the diffraction analysis presented is only valid when dealing with crystallites in the nanometric range, and therefore, in agreement with the SEM, TEM and BET measurements this could be only applied to $100 \mathrm{~h}$ wet milling. In fact, for the equivalent (in terms of crystallite size) $100 \mathrm{~h}$ dry milling and $75 \mathrm{~h}$ wet milling 


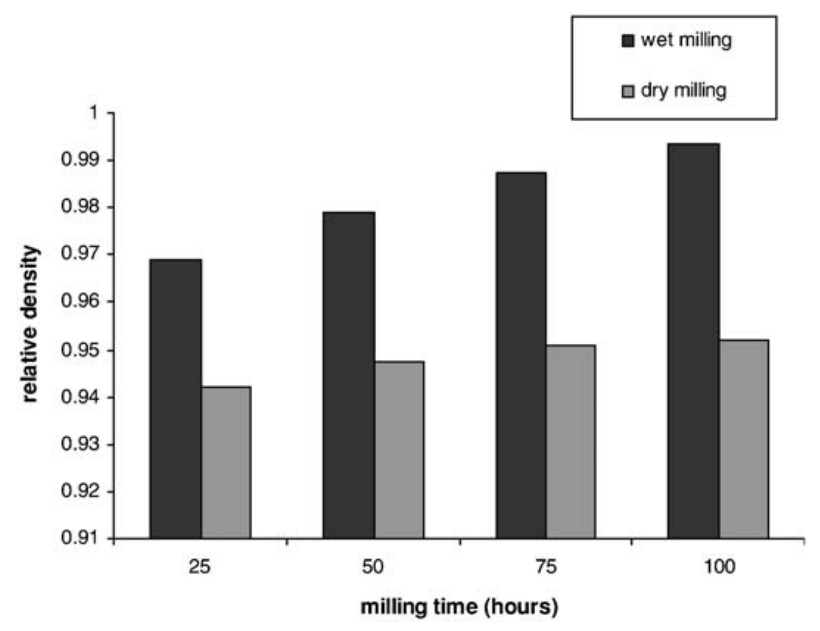

8 Relative density as function of milling time, for two routes used

processes, and using the Scherrer equation, crystallite mean values of 45 and $63 \mathrm{~nm}$ respectively have been calculated. Using the Stokes-Wilson equation yields a little higher crystallite sizes (91 and $98 \mathrm{~nm}$ respectively) with levels of internal stress of 0.48 and $0.35 \%$ respectively. Owing to the limit of applicability of these methods and the deviations with respect to SEM and TEM observations, these results have to be taken with some reserves. Still, these results confirmed the ultrafine size of these mixtures and the presence of crystallites with sizes of $100 \mathrm{~nm}$.

The analysis of the different WC diffraction peaks of the powder obtained after $100 \mathrm{~h}$ wet milling corroborated its nanocrystalline nature. In fact, using the Scherrer equation a mean crystallite size of $10 \mathrm{~nm}$ have been calculated. However, this value is dependant upon the peak considered, and presents a maximum of $15.5 \mathrm{~nm}$ for the basal plane $\{0001\}$ in the hexagonal WC structure, because the prismatic planes (specially $\{1010\}$ ) are the main planes involved in sliding and fracture of WC. ${ }^{1}$

When considering the Stokes-Wilson equation, a mean crystallite size of $19 \mathrm{~nm}$ was worked out, which is in agreement with the work by Butler et al. ${ }^{24}$ However, the level of internal stresses calculated is $0 \cdot 41 \%$, well

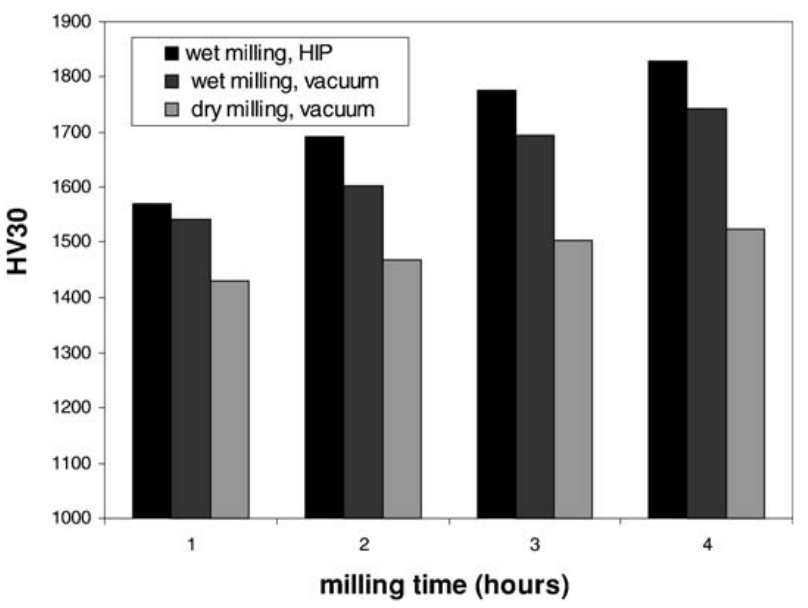

10 Vickers hardness values of WC-12Co materials consolidated as function of milling time and conditions, and sintering rout

below that obtained by Zhang et al. for a similar crystallite final size. ${ }^{1}$

Figure 8 shows the relative density of vacuum sintered WC-12Co materials as a function of the milling time and route. The densification of wet milled materials is significantly higher. The wet milled material for $100 \mathrm{~h}$ shows a relative density higher than $99 \%$. This is due to a better distribution of $\mathrm{Co}$ and organic binder. In addition, the minor grain size and high lattice distortion of the wet milling materials produces an increase in sintering activity, which allows a higher densification during the process. The wet milling material for $100 \mathrm{~h}$ shows relative density $5 \%$ higher than that of the dry milling material for the same time.

The wet milled materials show $\mathrm{A}<02, \mathrm{~B} 02$ and $\mathrm{C} 02$ porosity, while than the dry milled material presents A02-A04, B04 and C04 porosity. A good dispersion of organic binder is essential to avoid $C$-type macroporosity, critical aspect for quantity control of hardmetals.

The wet milled materials achieve full density when are consolidated by HIP. The porosity values obtained have been: $\mathrm{C} 00, \mathrm{~B}<02$ and $\mathrm{A}<02$. Although HIP is isostatically applied, local shear stress components appear at WC particle contact points. This effective stress,
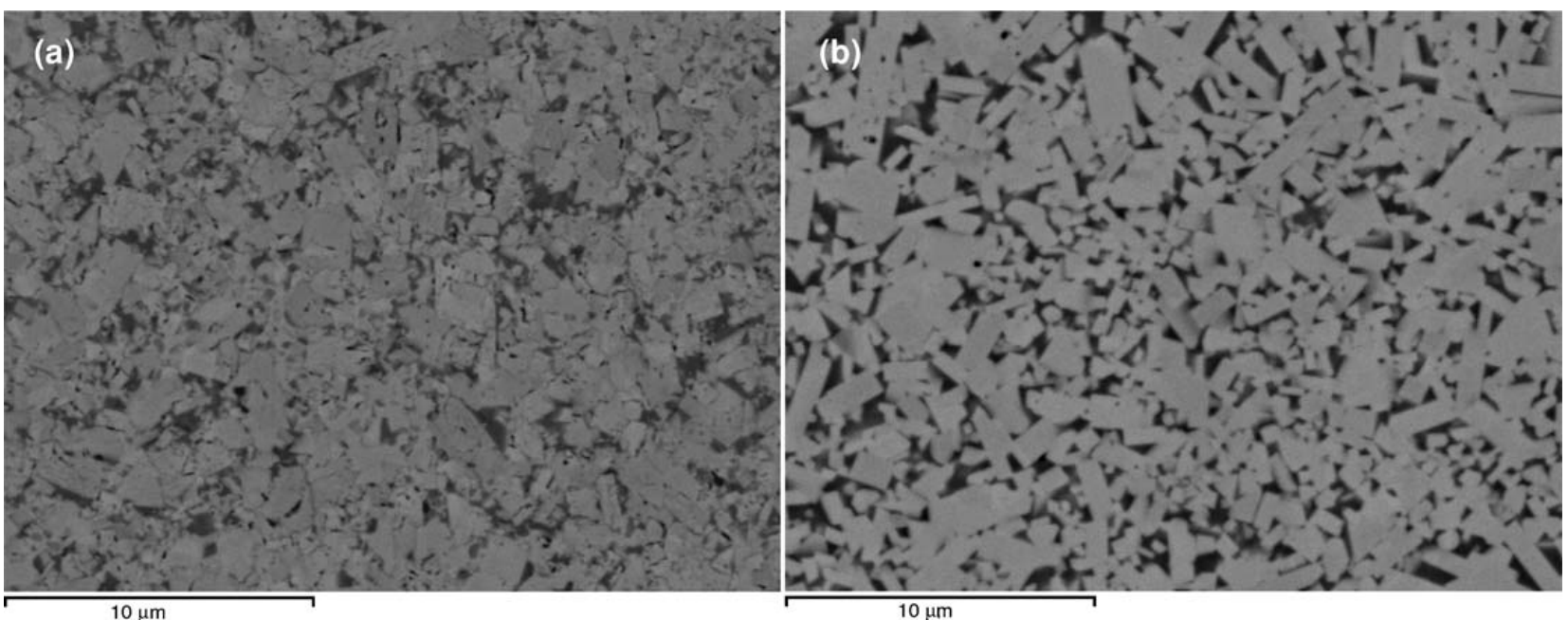

a vacuum at $1400^{\circ} \mathrm{C}$ for $60 \mathrm{~min} ; b \mathrm{HIP}$ at $1250^{\circ} \mathrm{C}, 1500 \mathrm{MPa}$ for $30 \mathrm{~min}$ 9 Images (SEM) as consolidated of WC-12Co wet milling for $100 \mathrm{~h}$ 


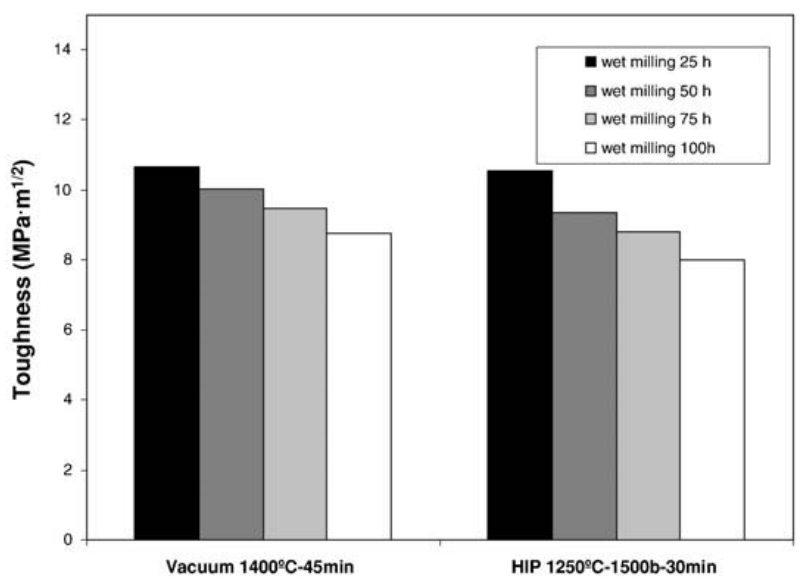

11 Toughness values of wet milling WC-12Co materials, after sintering by vacuum and HIP

caused by the high pressure difference between the outside and the inside of the glass capsule, can lead to cobalt plastic deformation and the collapse of the pore structure. $^{7}$

Images (SEM) of wet milling material for $100 \mathrm{~h}$, after vacuum sintering and HIP, are shown in Fig. 9. It can be seen that cobalt distribution is not perfect, reflecting poorer spreading when compared with liquid phase sintering. Fine microstructure has been obtained by low processing temperature. WC mean grain size smaller than $0.5 \mu \mathrm{m}$ has been measured. Thus, consolidation by HIP in solid state has been demonstrated as an effective method for controlling to grain growth of nanocrystalline $\mathrm{WC}-\mathrm{Co}$ mixtures.

Vickers hardness values for different materials obtained by vacuum sintering and HIP are presented in Fig. 10. The increase in the hardness of the wet milling materials is associated with the higher density and smaller grain size in the final microstructure, which is related to the major efficiency of the wet processing, in the distribution of constituents and the reduction of particle size in the powder mixture. High hardness values of the wet milling material for $100 \mathrm{~h}$ and vacuum sintered not only are justified by WC grain size (mean grain size of 0.7 ), and it is believed to be due to the hardening of binder phase for greater dissolution of $\mathrm{W}$ and C. Materials sintered by HIP show excellent hardness values, with differences of more than $8 \%$ compared to the processing in vacuum. This is due to full densification and the smaller grain size. Hardness higher than $1800 \mathrm{HV}$ has been obtained for the wet milled material for $100 \mathrm{~h}$.

The toughness values, obtained for different materials sintered by vacuum and HIP, are shown in Fig. 11. It is important to emphasise the toughness reduction in materials obtained from ultrafine and nanometric powder, which may be due to the hardening and embrittlement of the binder for the greater dissolution of $\mathrm{W}$ and $\mathrm{C}$, and probably to the formation of secondary phases ( $\eta$ and phases). The samples processed by HIP showed toughness slightly lower than those obtained by vacuum. The materials obtained by HIP from nanocrystalline powders showed lower toughness, it is due to the increase in hardness by the effect of grain size, and possibly by reducing the mean free path of Co and the increase in the contiguity between carbides in the absence of liquid phase. ${ }^{10}$

\section{Conclusions}

Planetary ball milling has been successfully used to reduce WC crystallite/particle size to obtain ultrafine and nanocrystalline $\mathrm{WC}-\mathrm{Co}$ mixtures.

A higher efficiency of the process was obtained when milling under wet conditions, obtaining ultrafine (100$250 \mathrm{~nm})$ and nanocrystalline $(10-60 \mathrm{~nm})$ mixtures after 75 and $100 \mathrm{~h}$ of milling respectively. In dry processing, cold welding phenomena of $\mathrm{Co}$ phase are more important than under the wet conditions leading to a lesser efficiency in crystallite size reduction. After $100 \mathrm{~h}$ milling time, only ultrafine powders are obtained.

For both dry and wet millings, process conditions minimise contamination phenomena and decarburisation, thus preventing oxidation and phase transformation.

The use of planetary ball milling with controlled process variables is a reasonable alternative to produce nanocrystalline $\mathrm{WC}-\mathrm{Co}$ mixtures.

Ultrafine and nanocrystalline powders obtained by wet milling show higher densification in conventional vacuum sintering. It is due to a better distribution of elements, and to the smaller grain size and high lattice distortion, which produces an increase in sintering activity. Very good mechanical properties have been obtained due to the high density and the absence of microstructural defects.

The materials obtained from nanocrystalline powders by HIP at low temperatures show excellent hardness and good toughness, as a result of full density and the controlling grain growth.

\section{Acknowledgement}

This work has been supported by CICYT, Spain, through project no. MAT2006-12945-C03-02.

\section{References}

1. F. L Zhang, C. Y. Wang and M. Zhu: Scr. Mater., 2003, 49, 11211128.

2. B. K. Kim, G. H. Ha and D. W. Lee: J. Mater. Process. Technol., 1997, 63, 317-321.

3. V. Chabretou, C. H. Allibert and J. M. Missiaen: J. Mater. Sci., 2003, 38, 2581-2590.

4. S. Berger, R. Porat and R. Rosen: Prog. Mater. Sci., 1997, 42, $311-$ 320 .

5. A. Parasiris and K. T. Hartwing: Int. J. Refract. Met. Hard Mater., 2000, 18, 23-31.

6. L. Bartha, P. Atató and A. L. Tóth: J. Adv. Mater., 2000, 32, 2326.

7. I. Azcona, A. Ordóñez, J. M. Sánchez and F. Castro: J. Mater. Sci., 2002, 37, 4289-4195.

8. D. F. Carroll: Int. J. Refract. Met. Hard Mater., 1999, 17, 123-132.

9. R. K. Sadangi, L. E. McCandish, B. H. Kear and P. Seegopaul: Int. J. Powder Metall., 1999, 35, (1), 27-33.

10. G. Gille, B. Szesny, K. Dreyer, H. van den Berg, J. Schmidt, T. Gestrich and G. Leitner: Int. J. Refract. Met. Hard Mater., 2002, 20, 3-22.

11. S. Liu, Z. L. Huang, G. Liu and G. B. Yang: Int. J. Refract. Met. Hard Mater., 2006, 24, 461-464.

12. M. S. El-Eskandarany, A. A. Mahday, H. A. Ahmed and A. H. Amer: J. Alloys Compd, 2000, 312, 315-325.

13. W. D. Schubert, A. Bock and B. Lux: Int. J. Refract. Met. Hard Mater., 1995, 13, 281-296.

14. P. Seegopaul, L. E. McCandlish and F. M. Shinneman: Int. J. Refract. Met. Hard Mater., 1997, 15, (1-3), 133-138. 
15. L. E. McCandish, H. B. Kear and J. S Bhatia: 'Spray conversion process for the production of nanophase composite powders', US patent no. 5352269, 1994

16. Z. Zhang, Y. Zhang and M. Muhammed: Int. J. Refract. Met. Hard Mater., 2002, 20, 227-233.

17. Z. Zhang, S. Wahlberg, M. Wang and M. Muhammed: Nanostruct. Mater., 1999, 12, 163-166.

18. L. Fu, L. H. Cao and Y. S. Fan: Scr. Mater., 2001, 44, 1061-1068.

19. Z. G. Ban and L. L. Shaw: J. Mater. Sci., 2002, 7, 3397-3403.

20. M. A. Xueming, Z. Ling, J. I. Gang and D. Yuanda: J. Mater. Sci. Lett., 1997, 16, 968-979.

21. M. A. Xueming, Z. Ling, J. I. Gang and D. Yuanda: J. Alloys Compd, 1998, 268, 267-270.
22. S. Mi and T. H. Courtney: Scr. Mater., 1997, 38, (1), 171-176.

23. J. Sun, F. Zhang and J. Shen: Mater. Lett., 2003, 57, 3140-3148.

24. B. G. Buther, J. Lu, Z. Z. Fang and R. Rajamani: Int. J. Powder Metall., 2007, 43, (1), 35-43.

25. S. H. Back, G. H. Lee and S. Kang: Mater. Trans., 2005, 46, (1), 105-110.

26. A. G. P. Da Silva, N. F. Da Silva and U. U. Gomes: Int. J. Powder Metall., 2001, 37, (6), 57-66.

27. H. G. Jiang, M. Rühle and E. J. Lavernia: J. Mater. Res., 1999, 14, (2), 549-559

28. D. Shetty, I. Wright and P. Mincer: J. Mater. Sci, 1985, 20, 1873-1882.

29. J. He, L. Ajdelsztajn, E. J. Lavernia: J. Mater. Res., 2001, 16, (2), $478-487$ 